\title{
Menstrual disorders necessitating counseling among students in Beni-Suef University
}

\author{
Hanan Elzeblawy Hassan*1, Wafaa Mostafa Ahmed Gamel ${ }^{2}$, Eman Ali Abd El Moaty Sheha ${ }^{3}$, Mervat Amin Sayed ${ }^{3}$, \\ Ahmed Emad Eldin Arafa ${ }^{4}$ \\ ${ }^{1}$ Maternal and Newborn Health Nursing, Faculty of Nursing, Beni-Suef University, Egypt \\ ${ }^{2}$ Maternal and Neonatal Health Nursing, Faculty of Nursing, Fayoum University, Egypt \\ ${ }^{3}$ Community Health Nursing, Faculty of Nursing, Fayoum University, Egypt \\ ${ }^{4}$ Department of Public Health, Faculty of Medicine, Beni-Suef University, Egypt
}

Received: October 11, 2018

DOI: $10.5430 /$ cns.v7n2p29
Accepted: December 28, $2018 \quad$ Online Published: January 10, 2019

URL: https://doi.org/10.5430/cns.v7n2p29

\begin{abstract}
Background: Menstrual disorders are highly prevalent among women. The need for counseling for different menstrual disorders is not well-documented.

Objective: This study aimed to investigate the prevalence of menstrual problems amongst Beni-Suef University students during the previous 6 months and detect what menstrual disorders required counseling more often.

Methods: A total of 1,519 students representing 28 different faculties of Beni-Suef University were included. To assess their menstrual disorders during the previous 6 months, a self-administered questionnaire was distributed to the university student. The questionnaire included questions about the most common complaints before and during menstruation. Other demographic and gynecological characters and the need for counseling were also investigated.

Results: The mean age of the participating university students was $20.9 \pm 1.7$ years. The mean age of their first menarche was $12.9 \pm 1.4$ years while their average menstrual flow days was $5.1 \pm 1.4$. Throughout the previous 6 months, $22.1 \%$ of the investigated university students reported counseling due to at least 1 menstrual disorder. Before the menstruation, irritation $(48.8 \%)$ and fatigue $(40.9 \%)$ were the most reported symptoms and associated with high rates of counseling while dysmenorrhea $(94.1 \%)$ and acne flare $(49.2 \%)$ were very common during menses. Students with menstrual cycles exceeding 28 days and those who experienced breast tenderness, abdominal bloating, and insomnia were statistically more likely to resort to counseling $(p<.05)$.
\end{abstract}

Conclusions: Menstrual disorders, especially dysmenorrhea, are very common among students in Beni-Suef University, however, the necessity of counseling varied widely according to the complaint.

Recommendations: Further studies should focus on the barriers to counseling for menstrual disorders.

Key Words: Counseling, Menstrual disorders, Dysmenorrhea, Students

\section{INTRODUCTION}

Women experience various physical, cognitive, and sexual stages of development and maturity. These stages are associated with coinciding gynecological and menstrual changes and these changes are more obvious during the second decade of life. ${ }^{[1]}$ Nationally, a significant percentage of the Egyptian population is youth, since two-thirds of the Egyptians are under 30 years and a quarter of them in the age between

\footnotetext{
*Correspondence: Hanan Elzeblawy Hassan; Email: nona_nano_1712@yahoo.com; Address: Maternal and Newborn Health Nursing, Faculty of Nursing, Beni-Suef University, Egypt.
}

Published by Sciedu Press 
15 and 29 years. Though the illiteracy rate is considerably high $(30 \%)$, a similar percent of the Egyptians is enrolled in different educational levels. ${ }^{[2]}$

During this critical stage when girls are physical, emotionally and sexually being less developed, and special attention is highly needed, many counseling approaches have been suggested. ${ }^{[1]}$ For most girls, menarche is a major milestone and the following menstrual changes and physical and emotional problems can be very irritating. ${ }^{[3]}$ Of these menstrual disorders, dysmenorrhea is the most common, being reported nationally, ${ }^{[4-9]}$ and internationally amongst up to $90 \%$ of women. ${ }^{[10-13]}$ Other premenstrual symptoms such as abdominal bloating, fatigue, irritation, have been investigated as well. ${ }^{[7-9,12]}$

Counseling for early detection and management of various menstrual disorders can improve the quality of life of the complaining women, mitigate their symptoms, and minimize the debilitating health problems. ${ }^{[14,15]}$ However, in developing communities where healthcare services are limited, underutilization of the appropriate healthcare service to women with menstrual disorders has been reported. ${ }^{[10,12,16]}$

\subsection{Significant of the study}

Nurses is comprising the greatest portion of the health-care system. Moreover, they are responsible of the quality of care provided to females' lifespan, that is why they have a very important role in counseling. ${ }^{[17]}$ The consultation is implemented by nursing nurses and teaching nurses. ${ }^{[18,19]}$ Nurses as a counselor should have the responsibilities of counseling, and provide guidance among students with menstrual disorders as it offers a great challenge in today's world. Maternity, gynecologic and community health nurses should be fitted with the appropriate sciences, knowledge, and skills that were necessary to help university students adjust to these monthly problem \& related difficulties. ${ }^{[18,20]}$

There is a little known on the need for counseling regarding menstrual disorders among university girls in Beni-Suef. Detecting the magnitude of menstrual problems amongst university students and which manifestations could be associated with the need for counseling can help in directing the appropriate resources towards these manifestations. Screening and counseling programs can be established based on a precise determination of the prevalence of the menstrual disorders and the necessity of counseling.

\subsection{Aim of the study}

The aim of this study was to investigate the prevalence of menstrual problems amongst Beni-Suef University students during the previous 6 months and detect what menstrual disorders required counseling more often.

\subsection{Research questions}

- What is the prevalence of menstrual problems amongst Beni-Suef University students 6 months ago?

- What menstrual disorders which required counseling?

- What is the prevalence of counseling regarding menstrual disorders among the participating students?

\section{SUBJECTS AND METHODS}

\subsection{Study design}

A cross-sectional design was used.

\subsection{Setting}

Beni-Suef University (28 different faculties; 12 faculties of humanities and social sciences, 9 faculties of various health sciences, and 7 faculties of computer sciences and engineering sciences).

\subsection{Period}

The study was conducted during the second semester of the academic year 2017/2018.

\subsection{Sampling}

The sample size was calculated using Epi-Info version seven Stat Calc, [Center for Disease Control (CDC), WHO], based on the following criteria: the counseling rate is $50.0 \%$, the confidence level is $95.0 \%$ and the margin of error is $5.0 \%$. The least sample size is 866 , however, we doubled the least sample size to enhance the statistical power (after doubling 1,732). A multi-stage random sampling technique was adopted to include students from all faculties and all scholastic years with a minimum of $5.0 \%$ per scholastic year. Of 1,732 were invited to the study; 1,519 responded giving us, a response rate of $87.7 \%$. The inclusion criteria were as follows: Affiliated to Beni-Suef University, Age 16-22 years, and Never used contraceptive methods. Students were excluded from the study if they were had reproductive system anatomical disorder, previous contraception usage, and gynecological disorders or treatment.

\subsection{Data collecting tool}

Researchers prepared an Arabic-language questionnaire. The questionnaire composed of 3 sections. Section I included 9 items, demographic characters: age, marital status, physical activity, and education of parents and menstrual history; the age of the first menarche, menstrual flow days, and the duration of menstrual cycle. Section II had questions about the history of dysmenorrhea (duration of menstrual cycle, prevalence of dysmenorrhea), other menstrual disorders, and premenstrual symptoms (irritation/nervousness, fatigue, breast tenderness, abdominal bloating, headache, nausea/vomiting, insomnia) and menstrual symptoms (dysmenorrhea, flow 
days $>4$ days, acne flare, dysuria, facial hair) during the past 6 months. Section III asked about the need for counseling due to any of the menstrual or premenstrual manifestations mentioned in section II.

\subsection{Pilot study}

Researchers conducted a pilot study on 150 students before putting the questionnaire in practice, and the Cronbach's alpha for the reliability was 0.76 and the content validity was judged by professors of Public Health and professors of Maternity, Gynecology and Obstetrics from the Faculties of Medicine and Nursing, Beni-Suef University.

\subsection{Data management}

Data were analyzed using the software, Statistical Package for Social Science (SPSS Inc. Released 2009, PASW Statistics for Windows, version 18.0: SPSS Inc., Chicago, Illinois, USA). Frequency distribution and descriptive were done. Chi-square $\left(\chi^{2}\right)$, odds ratio (OR) and $95.0 \%$ confidence interval $(\mathrm{CI})$ were calculated whenever needed. $P$ values of less than .05 were considered significant. Colum and 3D Pie chart were used for graphic presentation.

\subsection{Ethical considerations}

The protocol of the study has been approved by the Research Ethics Committee of Beni-Suef University, and then institutional approvals were sought. The students were informed of the purpose of the study with confirming the confidentiality of data. Verbal consents were obtained from the participants before data collection.

\section{Results}

Of the 1,519 university students who responded to the survey, $1,020(67.1 \%)$ were residing in urban areas and $499(32.9 \%)$ were living in rural areas. The mean age of the students was $20.9 \pm 1.7$ years and $78(5.1 \%)$ were married. Regarding the education of parents; $1,181(77.7 \%)$ of fathers were highly educated, $236(15.5 \%)$ completed their basic education, and only $102(6.7 \%)$ were illiterate. The same educational stages for mothers were $71.6 \%, 16.1 \%$ and $12.4 \%$, respectively. Additionally, the menarche mean age of the university girls was $12.9 \pm 1.4$ years, the duration of the menstrual cycle was $28.5 \pm 5.3$ days, and the mean flow days was $5.3 \pm$ 1.4 days. Only $21.5 \%$ of students were physically active (practice exercise regularly) during their menstruation (see Table 1).

The study revealed that $22.1 \%$ of participating university students required counseling due to at least 1 of their menstrual symptoms during the previous 6 months (see Figure 1).

Published by Sciedu Press
Table 1. Demographic and gynecological characteristics of the participating students $(n=1,519)$

\begin{tabular}{ll}
\hline Demographic and Gynaecological Data & $\mathbf{N}=\mathbf{1 , 5 1 9}$ \\
\hline Age; (Mean $\pm \boldsymbol{S D}$ ) years & $20.9 \pm 1.7$ \\
Residence & \\
- Urban & $1,020(67.1 \%)$ \\
- Rural & $499(32.9 \%)$ \\
Married (sexually active) & $78(5.1 \%)$ \\
Father's Education & \\
- Illiterate & $102(6.7 \%)$ \\
- Elementary & $236(15.5 \%)$ \\
- High & $1,181(77.7 \%)$ \\
Mother's Education & \\
- Illiterate & $188(12.4 \%)$ \\
• Elementary & $244(16.1 \%)$ \\
- High & $1,087(71.6 \%)$ \\
Physically Active (practice exercise regularly) & $327(21.5 \%)$ \\
Menarche Age; (Mean $\pm S D)$ years & $12.9 \pm 1.4$ \\
Menstrual Cycle Duration; (Mean $\pm S D)$ days & $28.5 \pm 5.3$ \\
Menstrual Flow Duration; (Mean $\pm S D)$ days & $5.1 \pm 1.4$ \\
\hline
\end{tabular}

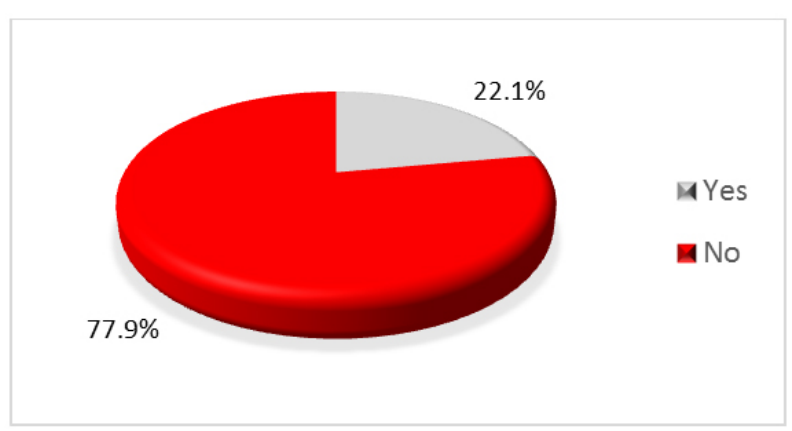

Figure 1. Prevalence of counseling due to menstrual disorders among the participating students $(n=1,519)$

Among the participating university students, $94.1 \%$ reported having dysmenorrhea during the previous 6 months, $49.2 \%$ reported acne flare, $48.8 \%$ had irritation and nervousness, $40.9 \%$ had fatigue, and $24.4 \%$ suffered from breast tenderness, $20.5 \%$ had a headache, $17.1 \%$ had abdominal bloating and $15.5 \%$ had nausea and vomiting. Dysuria, insomnia, and facial hair were less likely to be reported with 9.9\%, 9.6\%, and $5.9 \%$, respectively (see Figure 2).

Our results showed that menstrual cycle duration more than 28 days, breast tenderness, abdominal bloating, and insomnia were significantly more likely to necessitate counseling during the previous 6 months $(p<.05)$. However statistically insignificant, fatigue, dysmenorrhea, more flow days, and acne flare were likely to require counseling (see Table 2). 


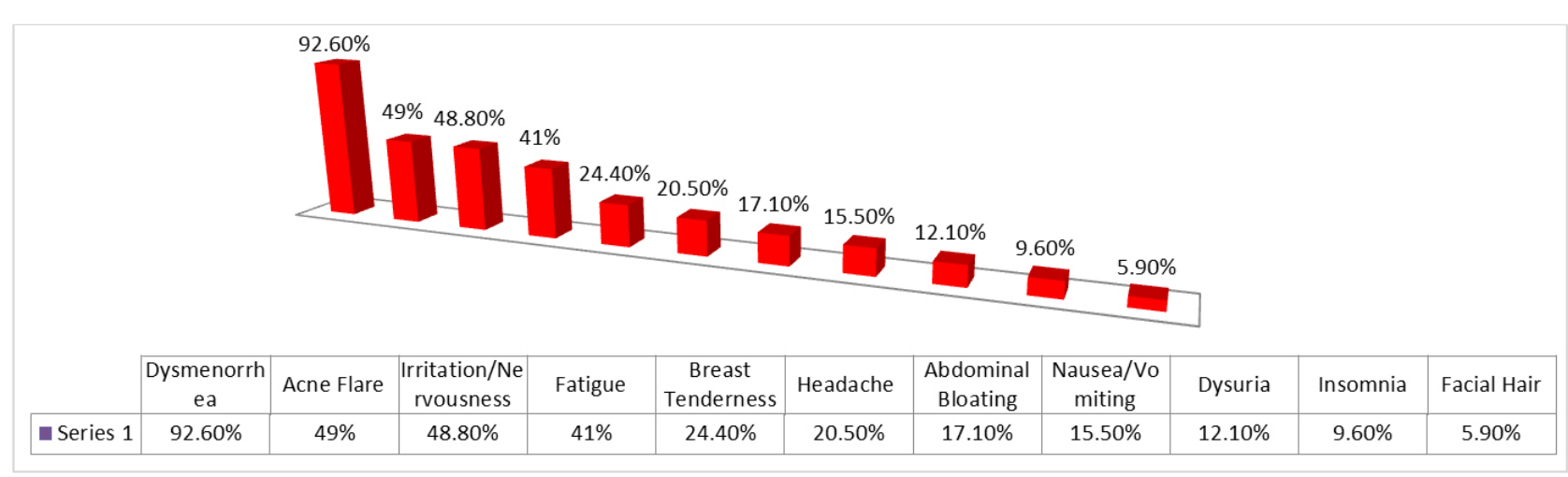

Figure 2. Prevalence of dysmenorrhea and different premenstrual symptoms among the participating students

Table 2. Menstrual disorders necessitating counseling among the participating students $(\mathrm{n}=1,519)$

\begin{tabular}{|c|c|c|c|c|}
\hline Menstrual Symptoms & $\begin{array}{l}\text { Counselling } \\
\mathrm{N}=336(\%)\end{array}$ & $\begin{array}{l}\text { No Counselling } \\
\mathrm{N}=1,183(\%)\end{array}$ & $p$ value & OR $(95 \% \mathrm{CI})$ \\
\hline Menstrual Cycle > 28 days & $159(47.3)$ & $421(35.6)$ & $<.001^{*}$ & $1.5(1.2-1.8)$ \\
\hline \multicolumn{5}{|l|}{ Premenstrual } \\
\hline - Irritation/Nervousness & $170(50.6)$ & $572(48.4)$ & .253 & $1.0(0.9-1.1)$ \\
\hline - Fatigue & $149(44.3)$ & $472(39.9)$ & .081 & $1.0(0.9-1.1)$ \\
\hline - Breast Tenderness & $100(29.8)$ & $271(22.9)$ & $.007^{*}$ & $1.1(1.0-1.2)$ \\
\hline - Abdominal Bloating & 77 (22.9) & $183(15.5)$ & $.001^{*}$ & $1.1(1.0-1.2)$ \\
\hline - Headache & $73(21.7)$ & $238(20.1)$ & .283 & $1.0(0.9-1.1)$ \\
\hline - Nausea/Vomiting & $55(16.4)$ & $181(15.3)$ & .344 & $1.0(0.9-1.1)$ \\
\hline - Insomnia & $51(15.2)$ & $95(8.0)$ & $<.001^{*}$ & $1.2(1.0-1.4)$ \\
\hline \multicolumn{5}{|l|}{ During Menstruation } \\
\hline - Dysmenorrhea & 315 (93.8) & $1,091(92.2)$ & .207 & $1.0(0.9-1.1)$ \\
\hline - Flow Days $>4$ days & 255 (75.9) & $848(71.7)$ & .071 & $1.0(0.9-1.1)$ \\
\hline - Acne Flare & $179(53.3)$ & $569(48.1)$ & .053 & $1.0(0.9-1.1)$ \\
\hline - Dysuria & $38(11.3)$ & $113(9.6)$ & .197 & $1.0(0.9-1.1)$ \\
\hline - Facial Hair & $21(6.3)$ & $69(5.8)$ & .430 & $1.0(0.9-1.1)$ \\
\hline
\end{tabular}

Note. ${ }^{*} p$ value is considered significant

Table 3. Relationship between counselling and demographic and gynecological characteristics of the participating students $(\mathrm{n}=1,519)$

\begin{tabular}{|c|c|c|c|}
\hline Demographic and Gynaecological Data & $\begin{array}{l}\text { Counselling } \\
\mathbf{N}=336\end{array}$ & $\begin{array}{l}\text { No Counselling } \\
N=1,183\end{array}$ & $p$ value \\
\hline Age; $($ Mean $\pm S D)$ years & $21.0 \pm 1.8$ & $20.9 \pm 1.7$ & .125 \\
\hline \multicolumn{4}{|l|}{ Residence } \\
\hline - Urban & $234(69.6 \%)$ & $786(66.4 \%)$ & \multirow{2}{*}{.150} \\
\hline - Rural & $102(30.4 \%)$ & $397(33.6 \%)$ & \\
\hline Married (sexually active) & $19(5.7 \%)$ & $59(5.0 \%)$ & .356 \\
\hline \multicolumn{4}{|l|}{ Father's Education } \\
\hline - Illiterate & $22(6.5 \%)$ & $80(6.8 \%)$ & \multirow{3}{*}{.655} \\
\hline - Elementary & $47(14.0 \%)$ & $189(16.0 \%)$ & \\
\hline - High & $267(79.5 \%)$ & $914(77.3 \%)$ & \\
\hline \multicolumn{4}{|l|}{ Mother's Education } \\
\hline - Illiterate & $39(11.6 \%)$ & $149(12.6 \%)$ & \multirow{3}{*}{.387} \\
\hline - Elementary & $62(18.5 \%)$ & $182(15.4 \%)$ & \\
\hline • High & $235(69.6 \%)$ & $852(72.0 \%)$ & \\
\hline Physically Active & $74(22.0 \%)$ & $253(21.4 \%)$ & .427 \\
\hline Menarche Age; $($ Mean $\pm S D)$ years & $13.0 \pm 1.6$ & $12.9 \pm 1.4$ & .809 \\
\hline
\end{tabular}


However, counselling regarding menstrual disorders was more prevalent among urban, students who have highly educated parents, and students' physical activity. There is insignificant statistically relation between counselling and demographic and gynecological characteristics of the participating students (see Table 3).

\section{Discussion}

This study investigated the necessity of counseling for different menstrual disorders among the students in Beni-Suef University, Egypt. The study showed that the attitude of seeking counseling for menstrual disorders in Beni-Suef was significantly poor. Although menstrual disorders pose many debilitating health and emotion impacts, only $22.1 \%$ of our study sample sought counseling for their symptoms during the past 6 months. The possible explanations for that are the lack of resources, embarrassment, maybe women find it "normal", and some girls may be having an embarrassment to talk about menstrual disorders as a result of family and community culture especially in closed communities as Upper Egypt.

Concerning to demographic characteristics of the studied sample, the present study revealed that the mean age of the students was $20.9 \pm 1.7$ years, $5.1 \%$ of students were married, highly educated father and mother $77.7 \%, 71.6 \%$ respectively, only $21.5 \%$ of student perform physical activity during menses. This finding is in accordance with the results of previous studies reported that the mean age of respondents studied was $20.8 \pm 2.7$ years, $\left(98.4 \%\right.$ ) were single. ${ }^{[21]}$ In another study, the mean age of the participant was $20.4 \pm$ 1.2 years and most $(92.3 \%)$ of them were single in marital status. ${ }^{[22]}$

This study showed that most of students' parents $(77.7 \%$ \& $71.6 \%$ ), respectively, had higher education, $21.5 \%$ of students were physically active during their menstruation. This may be attributed that, the mother's educational status, in general, may alter the premenstrual syndrome (PMS) of their daughters. Educational status of mothers with a certificate and above is most likely to reduce PMS in their daughters by $55.0 \%$ than illiterate mothers $(\mathrm{AOR}=0.45,95.0 \%, \mathrm{CI}: 0.25$, $0.83)$. Mean age of study participants was calculated to be 16.2 years. The daily routine of more than half $(60.0 \%)$ of young females was affected due to prolonged bed rest, and missed social activities. ${ }^{[23]}$

The menarche mean age of the university students in the present study was $12.9 \pm 1.4$ years, the duration of the menstrual cycle was $28.5 \pm 5.3$ days, and the mean flow days was $5.3 \pm 1.4$. Our results are similar to the other studies that have been done in recent years which reported, the mean age

Published by Sciedu Press at menarche was $13.6 \pm 1.1$ years, the duration of menstrual flow was 3 to 5 days among $78.9 \%$ of respondents, while it flows for more than 5 days among $12.6 \% .^{[21]}$ The mean age of the participants' menarche was $12.8 \pm 1.3$ years with a range from 9 to 17 years. ${ }^{[24]}$ The interval between two periods and the menstrual flow days were $27.7 \pm 2.5$ days and $5.8 \pm 1.4$ days, respectively. ${ }^{[11]}$ The age at menarche was ranged from 10 to 19 years old with a mean of $14.7 \pm$ 1.6 years. ${ }^{[22]}$ The studies were done by Singh in New Delhi, India, Zegeye in Ethiopia, Verma in Bhavnagar found that, the mean ages of menarche were $12.5,14.8 \& 14$ years old, respectively. ${ }^{[25-27]}$ The observed difference was probably due to geographical variation and socio-economic variation in the study subjects.

A previous Egyptian study on secondary school students with menstrual disorders revealed that only $2.7 \%$ of the students required healthcare consultation for their menstrual disorders. ${ }^{[5]}$ The current study revealed that $22.1 \%$ among the participating students sought out for the counseling for their menstrual disorders. Although this result was in-accordance with several national and international results, it contradicted results of other studied. A national study reported that Egyptian girls aged $12-25$ years showed that $22.4 \%$ of participants with dysmenorrhea and $22.6 \%$ of those with premenstrual disorders visited a physician for a gynecological complaint. ${ }^{[9]}$ Another study on Turkish girls reported that $18.0 \%$ of all girls with dysmenorrhea had consulted a doctor due to pain. ${ }^{[11]}$ Also, Waghachavare reported that $36.13 \%$ of the student suffering from any menstrual problems had consulted to doctor at some point of time, more than $70.0 \%$ supported the need of health counselor or health-cell in college. ${ }^{[28]}$ Moreover, our result was better than other results as in India, Sharma reported that, generally, only $4.0 \%$ of young females took the professional advice for their menstrual disorders from a doctor. And about one-tenth of his respondents had consulted a health-facility for their menstrual related problems. ${ }^{[23]}$ Santina declared in his research that, only $7.5 \%$ of the students decided to seek medical attention for menstrual abnormalities in other reports. ${ }^{[29]}$

This low counseling rate has also been reported in many international studies. In Nigeria, a study on schoolgirls showed that only $10.6 \%$ of the participants were residing in a rural areas and $13.6 \%$ of the participants from urban areas counseled a health-care provider due to their menstrual symptoms. ${ }^{[16]}$ Similar findings from Malaysia $(11.1 \%)^{[10]}$ and India $(6.5 \%)$ have been published as well. ${ }^{[12]}$

However, such low rates of counseling could be explained by the conservative nature of the community that does not endorse the approach of counseling health-care providers for 
menstrual disorders. A previous report showed that many factors could hinder the counseling attitude such as the discomfiture by personal questions and the male gender of the doctor. $^{[12]}$ Another study reported that most the women refuse gynecological examination by a male physician as they felt uncomfortable with male physician. They provided causes such as, religious, beliefs, unwillingness to discuss sensitive and confidential situation with a male physician. In addition, studied young student reaction of embarrassment \& shame. ${ }^{[30]}$ Meanwhile, it is essential to detect the barriers to seek counseling by young women for their menstrual disorders.

The study revealed that dysmenorrhea represented in $92.6 \%$ of girls. It was the main complaint among different premenstrual symptoms of the participating university students. A similar percentage (94.2\%) reported in El-Minia university. ${ }^{[8]}$ High prevalence of dysmenorrhea was also reported by Campbell \& McGrath $(93.0 \%)$ and Banikarim et al. (85.0\%). ${ }^{[31,32]}$ Additionally, Cakir reported that the prevalence found in a study conducted among university students of Turkey which were $89.5 \% .^{[11]}$ Other national studies showed relatively lower rates; $75 \%$ in El-Mansoura, ${ }^{[5]}$ and $76.1 \%$ in Assiut. ${ }^{[6]}$ Otherwise, our result contradicted and was higher than a study, conducted among secondary school students of Northern Ethiopia, which reported that $72.0 \%$ of students complained from dysmenorrhea. ${ }^{[26]}$ It was also higher than the findings found in countries out of Africa and in Africa which was between $59.7 \%$ and $85 \%$. ${ }^{[26,33]}$ Studies from Lebanon, ${ }^{[34]}$ Sangli, ${ }^{[28]}$ Saudi Arabia, ${ }^{[13]}$ and India, ${ }^{[25,35]}$ Turkey ${ }^{[36]}$ and Northwest Ethiopia ${ }^{[26]}$ showed even lower rates; $38.1 \%, 42.5 \%, 60.9 \%, 67.2 \%, 73.83 \%, 67.2 \%$ and $72 \%$ respectively. These differences may be attributed to that, the students' age range in which the prevalence of menstrual disorders and dysmenorrhea increase or decrease. Otherwise, it could be related with the stress of the university students which has psychological impact, and in-turn may induce dysmenorrhea.

However, the lack of a universally accepted definition for dysmenorrhea and the fact that many personal, social, and environmental factors could affect the occurrence of dysmenorrhea could explain these variations. Further, this study assessed dysmenorrhea during the past 6 months compared to shorter spans in the other studies.

Our results showed that acne flare, fatigue, and irritation were very common menstrual symptoms as reported by the participating university girls. This coincided with previous studies which detected these symptoms as common symptoms sided by side with dysmenorrhea. ${ }^{[5,9,11,37,38]}$ While backache, nervousness, abdominal bloating, insomnia, facial hair were less common menstrual symptoms as reported by the participating university girls. This result isn't coinciding with previous studies. ${ }^{[1,12]}$ Moreover, another Egyptian study declared that mood swings, tiredness, back-pain are the most common students' complaints and symptoms associated with menstrual cycle, followed by loss of appetite, headache, and stomach pain. Diarrhea, breast tenderness, profuse sweating, increase weight, inability to concentration, and facial puffiness are less common manifestations. ${ }^{[8]}$ Further, longer menstrual cycle, abdominal bloating, breast tenderness, and dysmenorrhea associated with a likelihood of counseling. Dysmenorrhea and irregular long cycles have many health, social, and emotional negative consequences. They also affect the work life, undermine the productivity, and result in a poor quality of life. ${ }^{[39-41]}$ These noisy consequences must have encouraged the university students to look for counseling.

Regarding the relationship between counseling and demographic \& gynecological characteristics of the participating students, the results of the current study revealed that seeking counseling was affected by students' age. Older students $(21.0 \pm 1.8)$ were more careful for counseling than younger ones $(20.9 \pm 1.7)$. Certainly, the residence is a main factor which affects seeking counseling. It was observed that $69.6 \%$ of students who sought counselling were urban dwellers. It is expected as residences may affect the availability of health-care centers and health-care providers.

Moreover, parents' education, especially mother, undoubtedly affects seeking counseling. It was observed that, the more parents' educational level, the more seeking counseling by students and vice versa. Educated mother plays a very crucial rule role in her daughter's perception regarding monarch, menstrual disorders, and seeking counseling. This might be attributed to a well-educated mother can discuss the menstrual problems more freely with their daughters than less educated/illiterate ones which in-turn could help daughters to understand the problem better, and cope up with the problem better than those who had not enjoy a free discussion with mothers. Also in the traditional culture, there is a crucial restriction in discussing of menstrual issues for young girls neither with friends nor physicians, especially in closed/rural areas. In the same context, girls who were pre-counseled on menarche were 2.2 times less likely to be caught unaware of menarche compared to those who weren't counseled, Similarly, those who were pre-counseled about menarche were 1.4 times more likely to have prepared for menstruation and twice less likely to have had disruptions of school activities Compared to those who weren't pre-counseled. ${ }^{[21]}$ 


\section{Conclusions}

In conclusion, menstrual disorders, especially dysmenorrhea, are highly prevalent among students in Beni-Suef, University, but there are striking deficits in the counseling for these disorders. Increasing the average age of the girl indicates that she will open her awareness of these problems and her housing in the urban area provides health awareness in more broadly than the countryside or rural area. Additionally, more parents' educational level, the more seeking counseling by students and vice versa, however, this was not statistically significant.

\section{Recommendations}

We recommend that future studies should concentrate on detecting the barriers to counseling for menstrual disorders. Awareness programs and interventions should address the necessity of counseling for menstrual disorders and assess the improvements after counseling.

\section{CONFLICTS OF INTEREST Disclosure}

The authors declare they have no conflicts of interest.

\section{REFERENCES}

[1] Hillard PA. Menstruation in adolescents: What's normal? What's not? The Medscape Journal of Medicine. 2008; 10(12): 295.

[2] Central Agency for Public Mobilization and Statistics (CAPMAS) statistical book. 2017. Available from: http://www. capmas.gov.eg/Pages/ShowPDF . aspx?pag e_id=/Admin/Pages\%20Files/201710914947book.pdf

[3] Acharya A, Reddaiah VP, Baridalyne N. Nutritional status and menarche in adolescent girls in an Urban Resettlement colony of South Delhi. Indian J Community Medicine. 2006; 31: 302-3.

[4] Arafa A, Senosy S, Helmy H, et al. Prevalence and patterns of dysmenorrhea and premenstrual syndrome among Egyptian girls (12-25 years). Middle East Fertil Soc J. 2018. https://doi .org/10.101 6/j.mefs.2018.01.007

[5] El-Gilany A, Badawi K, El-Fedawy S. Epidemiology of dysmenorrhea among adolescent students in Mansoura, Egypt. Eastern Mediterranean Health Journal. 2005; 11(1): 155-63. PMid: 16532684.

[6] Mohamed E. Epidemiology of dysmenorrhea among adolescent students in Assiut City, Egypt. Life Sci J. 2012; 9(1): 348-53.

[7] Nooh A. Menstrual disorders among Zagazig University students Zagazig, Egypt. Middle East Fertil Soc J. 2015; 20(3): 198-203. https://doi.org/10.1016/j.mefs . 2014.08.002

[8] Emem E, Hassan H. Correlation between Quality of Life and Dysmenorrhea among Nursing Schools Students. International Journal of Nursing Science. 2017; 7(6): 123-132.

[9] Arafaa A, Khamis Y, Hassan H, et al. Epidemiology of dysmenorrhea among workers in Upper Egypt; A cross sectional study. Middle East Fertility Society Journal. 2018; 23(1): 44-47. https : //doi.org/10.1016/j.mefs.2017.07.002

[10] Lee L, Chen P, Lee K, et al. Menstruation among adolescents' girls in Malaysia: a cross-sectional school survey. Singapore Med J. 2006 47: 869-74. PMid: 16990962.

[11] Cakir M, Mungan I, Karakas T, et al. Menstrual pattern and common menstrual disorders among university students in Turkey. Pediatr Int 2007; 49(6): 938-42. PMid: 18045301. https://doi.org/10.1 111/j.1442-200X.2007.02489.x

[12] Chan S, Yiu K, Yuen P, et al. Menstrual problems and health-seeking behavior in Hong Kong Chinese girls. Hong Kong Med J. 2009; 15: 18-23. PMid: 19197092.

[13] Ibrahim N, AlGhamdi M, Al-Shaibani A, et al. Dysmenorrhea among female medical students in King Abdulaziz University: prevalence, predictors and outcome. Pak J Med Sci. 2015; 31(6): 1312-7. PMid: 26870088. https://doi.org/10.12669/pjms.316.8752
[14] Houston A, Abraham A, Huang Z, et al. Knowledge, attitudes, and consequences of menstrual health in urban adolescent females. J Pediatr Adolesc Gynecol. 2006; 19(4): 271-5. PMid: 16873031 https://doi.org/10.1016/j.jpag. 2006.05.002

[15] Kadir R, Edlund M, Von Mackensen S. The impact of menstrual disorders on quality of life in women with inherited bleeding disorders. Haemophilia. 2010; 16(5): 832-9. PMid: 20584085. https : //doi.org/10.1111/j.1365-2516.2010.02269.x

[16] Ibanga E. Health seeking behaviour for menstrual problems among school girls and its associated factors: an implication for health education. International Journal of Current Research. 2015; 7(8): 19638-44.

[17] Sheha E, Hassan H, Gamel W. Association between pre-pregnant overweight and obesity and periodontal disease during pregnancy: a cross sectional study. International Journal of Studies in Nursing. 2018; 3(1): 1-21. https://doi.org/10.20849/ijsn.v3i1. 207

[18] Hassan H, Saber N, Sheha E. Comprehension of dyspareunia and related anxiety among Northern Upper Egyptian women: Impact of nursing consultation context using PLISSIT model. Nursing \& Care Open Access Journal. 2019; 6(1): 1-19.

[19] Ishak I, Low W, Othman S. Prevalence, risk factors and predictors of female sexual dysfunction in a primary care setting: A survey finding. J Sex Med. 2014; 7: 3080-3085. PMid: 20584130. https://doi.org/10.1111/j.1743-6109.2010.01848.x

[20] Hassan H. Infertility profile, psychological ramifications and reproductive tract infection among infertile women, in northern Upper Egypt. Journal of Nursing Education and Practice. 2016; 6(4): 92108. https://doi.org/10.5430/jnep.v6n4p92

[21] Adebimpe W, Farinloye E, Adeleke N. Menstrual Pattern and Disorders and Impact on Quality of Life Among University Students in South-Western Nigeria. Journal of Basic and Clinical Reproductive Sciences. Wolters Kluwer Medknow. 2016; 5(1): 27-32.

[22] Shiferaw M, Wubshet M, Tegabu D. Menstrual problems and associated factors among students of Bahir Dar University, Amhara National Regional State, Ethiopia: A cross-sectional survey. The Pan African Medical Journal. 2014. PMid: 25309646. https: //doi.org/10.11604/pamj.2014.17.246.2230

[23] Sharma A, Taneja DK, Sharma P, et al. Problems related to menstruation and their effect on daily routine of students of a medical college in Delhi, India. Asia Pac J Public Health. 2008; 20: 234-41. PMid: 19124317. https://doi.org/10.1177/1010539508316939

[24] Ersoy B, Balkan C, Gunay T, et al. Effects of different socioeconomic conditions on menarche in Turkish female students. Early Hum. Dev. 
2004; 76: 115-25. PMid: 14757263. https://doi.org/10.1016/ j.earlhumdev. 2003.11.001

[25] Singh A, Kiran D, Singh H, et al. Prevalence and severity of dysmenorrhea: a problem related to menstruation, among first and second yearfemale medical students. Indian J Physiol Pharmacol. 2008; 5: 389-97.

[26] Zegeye DT, Megabiaw B, Mulu A. Age at menarche and the menstrual pattern of secondary school adolescents in northwest Ethiopia. BMC Women's Health. 2009; 9: 1-8. PMid: 19804623. https: //doi.org/10.1186/1472-6874-9-29

[27] Verma PB, Pandya CM, Ramanuj VA, et al. Menstrual Pattern of Adolescent School Girls of Bhavnagar (Gujarat). NJIRM. 2011; 2 : 38-40. Available from: http://www. scopemed.org/?mno=6468

[28] Waghachavare V, Chavan V, Dhumale G. A study of menstrual problems among the female Junior college students from rural area of sangli district. National Journal of Community Medicine. 2013; 4(2): 236-240.

[29] Santina T, Wehbe N, Ziade F. Exploring dysmenorrhoea and menstrual experiences among Lebanese female adolescents. East Mediterr Health J. 2012; 18: 857-63. PMid: 23057375. https : //doi .org/ 10.26719/2012.18.8.857

[30] Eid S, Hassan H, Fathy W, et al. Study Women Verbal and Nonverbal Response, During Their First Gynecological Examination. American Journal of Nursing Research. 2019; 7(1): 1-7.

[31] Campbell MA, McGrath PJ. Non-pharmacologic strategies used by adolescents for the management of menstrual discomfort. Clin. J. Pain. 1999; 15: 313-20. PMid: 10617260. https://doi.org/10 .1097/00002508-199912000-00008

[32] Banikarim C, Chacko MR, Kelder SH. Prevalence and impact of dysmenorrhea on Hispanic female adolescents. Arch. Pediatr. Adolesc. Med. 2000; 154: 1226-9. PMid: 11115307. https://doi.org/10 $.1001 /$ archpedi.154.12.1226
[33] Tangchai K, Titapant V, Boriboonhirunsarn D. Dysmenorrhea in Thai adolescents: prevalence, impact and knowledge of treatment. J Med Assoc Thai. 2004; 87(3): 69-73.

[34] Karout N, Hawai SM, Altuwaijri S. Prevalence and pattern of menstrual disorders among Lebanese nursing students. East Meditter Health. 2012; 18(4): 346-52. https ://doi .org/10. 26719/2012. 18.4 .346

[35] Jailkhani S, Naik J, Thakur M, et al. Patterns \& problems of menstruation amongst the adolescent girls residing in the Urban Slum. Sch. J App Med Sci. 2014; 2(2A): 529-34.

[36] Sharma P, Malhotra C, Taneja DK, et al. Problems related to menstruation amongst adolescent girls. Indian J Pediatr. 2008; 75: 125-9. https://doi.org/10.1007/s12098-008-0018-5

[37] Kircan N, Ergin F, Adana F, et al. The prevalence of premenstrual syndrome in nursery students and its relationship with quality of life. Adnan Menderes Üniversitesi Tip Fakültesi Dergisi. 2012; 13: 19-25.

[38] Olowokere A, Oginni M, Olajubu A, et al. Menstrual disorders: The implications on health and academic activities of female undergraduates in a federal university in Nigeria. Journal of Nursing Education and Practice. 2014; 4(5): 126-135. https://doi.org/10.5430/ jnep.v4n5p126

[39] Shaw R, Brickley M, Evans L, et al. Perceptions of women on the impact of menorrhagia on their health using multi-attribute utility assessment. British Journal of Obstetrics and Gynaecology. 1998; 105(11): 1155-9. PMid: 9853763. https://doi.org/10.1111/j . 1471-0528.1998.tb09968.x

[40] Barnard K, Frayne S, Skinner K, et al. Health status among women with menstrual symptoms. J Women's Health (Larchmt). 2003; 12: 911-9. PMid: 14670171. https://doi.org/10.1089/15409990 3770948140

[41] Tasci K. Evaluation of nursing students' premenstrual symptoms. TAF Prev Med Bull. 2006; 5: 434-43. 